\title{
Early detection of cystic fibrosis lung disease: multiple-breath washout versus raised volume tests
}

\section{Sooky Lum, Per Gustafsson, Henrik Liungberg, Georg Hülskamp, Andrew Bush, Siobhán B Carr, Rosemary Castle, Ah-fong Hoo, John Price, Sarath Ranganathan, John Stroobant, Angie Wade, Colin Wallis, Hilary Wyatt, Janet Stocks on behalf of the London Cystic Fibrosis Collaboration}

Thorax 2007;62:341-347. doi: 10.1136/thx.2006.068262
See end of article for authors' affiliations

Correspondence to: Dr S Lum, Portex Anaesthesia, Intensive Therapy and Respiratory Medicine Unit, UCL, Institute of Child Health, 30 Guilford Street, London WCIN 1EH, UK; s.lum@ich.ucl.ac.uk

Received 3 July 2006 Accepted 18 October 2006

\begin{abstract}
Background: Lung clearance index (LCl), a measure of ventilation inhomogeneity derived from the multiplebreath inert gas washout (MBW) technique, has been shown to detect abnormal lung function more readily than spirometry in preschool children with cystic fibrosis, but whether this holds true during infancy is unknown.

Objectives: To compare the extent to which parameters derived from the MBW and the raised lung volume rapid thoraco-abdominal compression (RVRTC) techniques identify diminished airway function in infants with cystic fibrosis when compared with healthy controls.

Methods: Measurements were performed during quiet sleep, with the tidal breathing MBW technique being performed before the forced expiratory manoeuvres.

Results: Measurements were obtained in 39 infants with cystic fibrosis (mean (SD) age 41.4 (22.0) weeks) and 21 controls (37.0 (15.1) weeks). Infants with cystic fibrosis had a significantly higher respiratory rate (38 (10) vs $32(5) \mathrm{bpm})$ and $\mathrm{LCl}(8.4(1.5)$ vs $7.2(0.3))$, and significantly lower values for all forced expiratory flow-volume parameters compared with controls. Girls with cystic fibrosis had significantly lower forced expiratory volume $\left(\mathrm{FEV}_{0.5}\right.$ and $\mathrm{FEF}_{25-75}$ ) than boys (mean $(95 \% \mathrm{Cl}$ girls-boys): $-1.2(-2.1$ to -0.3$)$ for $\mathrm{FEV}_{0.5} \mathrm{Z}$ score; $\mathrm{FEF}_{25-75}:-1.2(-2.2$ to -0.15$\left.)\right)$. When using both the MBW and RVRTC techniques, abnormalities were detected in $72 \%$ of the infants with cystic fibrosis, with abnormalities detected in $41 \%$ using both techniques and a further $15 \%$ by each of the two tests performed.

Conclusions: These findings support the view that inflammatory and/or structural changes in the airways of children with cystic fibrosis start early in life, and have important implications regarding early detection and interventions. Monitoring of early lung disease and functional status in infants and young children with cystic fibrosis may be enhanced by using both MBW and the RVRTC.
\end{abstract}

$\mathrm{R}$ ecently there has been increasing interest in assessing lung function in infants and preschool children to detect early cystic fibrosis lung disease. ${ }^{1-6}$ Parameters derived from forced expiratory manoeuvres have traditionally been used to monitor lung function in older patients with cystic fibrosis and forced expiratory volume in 1 second $\left(\mathrm{FEV}_{1}\right)$ is still considered to be a predictor of prognosis in patients with moderate to severe cystic fibrosis lung disease. ${ }^{78}$ Although infants cannot perform such manoeuvres, forced expiratory flow-volume (FEFV) loops can be obtained by substituting voluntary effort with application of an external pressure to the chest and abdomen to force expiration. Adaptations of these measurements have enabled "full" forced expiratory manoeuvres using the raised lung volume rapid thoraco-abdominal compression (RVRTC) technique to be obtained from sleeping infants.? Forced flows and volumes obtained over an extended volume range (from near total lung capacity) have been shown to be more sensitive in detecting diminished airway function in infants with cystic fibrosis than the tidal rapid thoracic compression technique. ${ }^{10-12}$ By contrast, several studies have shown that many younger children with cystic fibrosis have spirometry results that fall within the normal range, ${ }^{4}{ }^{13} 14$ and that indices of gas mixing derived from inert gas multiplebreath washout (MBW) may be more sensitive than spirometry in detecting early airway disease in both preschool and schoolage children with cystic fibrosis. ${ }^{14}{ }^{15}$

Reduced gas mixing efficiency or "increased inhomogeneity in ventilation" can result from differences in specific ventilation between lung units joined at branch points in the conducting airways. It can also result from interaction between convective and diffusive mixing, owing to geometrical asymmetries, including unequal narrowing of airways at branch points in the lung periphery close to the gas exchange zone. ${ }^{16}{ }^{17}$ Disease processes that affect the peripheral airways will therefore lead to increased ventilation inhomogeneity. One of the indices of ventilation inhomogeneity that can be derived from the MBW is the lung clearance index (LCI), a measure of gas mixing efficiency calculated from the relative ventilation required to clear a tracer gas from the lung. ${ }^{14}{ }^{16}$ We have previously shown that the LCI detects abnormal lung function more readily than spirometry in preschool ${ }^{1}$ and school-age childre ${ }^{4}{ }^{13}$ with cystic fibrosis, but whether this is true during infancy is unknown. It is particularly important to establish which test(s) should be used in specific clinical scenarios during infancy owing to the complexity of these measurements and limited period of sleep in which to complete all assessments. Our hypothesis was that in infancy, LCI would also be more sensitive than forced expiratory manoeuvres. Therefore, the aim of this study was to compare the extent to which parameters derived from the MBW and RVRTC techniques identify diminished airway

Abbreviations: FEF, forced expiratory flow; FEFV, forced expiratory flowvolume; FEV, forced expiratory volume; FRC, functional residual capacity; FVC, forced vital capacity; LCl, lung clearance index; MBW, multiplebreath washout; RR, respiratory rate; RVRTC, raised lung volume rapid thoraco-abdominal compression; $\mathrm{SF}_{6}$, sulphur hexafluoride 
function in a cohort of infants with cystic fibrosis when compared with healthy controls.

\section{METHODS}

Infants and young children, diagnosed with cystic fibrosis before 2 years of age, were recruited to this study towards the end of the first phase of the London Cystic Fibrosis Collaboration from five specialist cystic fibrosis centres in London. ${ }^{6}$ Results from these infants have not been published previously. Healthy controls born at the Homerton University or University College hospitals in London, UK, were recruited as part of ongoing epidemiological studies. ${ }^{18}{ }^{19}$ All subjects were tested at the infant respiratory laboratory at the Institute of Child Health (London, UK) using identical equipment and protocols. Subjects with a history of respiratory illness requiring hospitalisation, congenital abnormalities and assisted ventilation or gestational age $<36$ weeks were ineligible. The study was approved by the North Thames Multi-Centre research ethics committee and the local research ethics committees of the participating hospitals, and informed written consent was obtained from all parents. For children with cystic fibrosis, information on genotype, date of diagnosis, mode of presentation and previous respiratory infection was obtained from the clinical centre.

Attempts were made to test all subjects at least 3 weeks after any respiratory tract infection. Testing needed to be rescheduled on several occasions for two infants with cystic fibrosis who had repeated respiratory exacerbations. A decision was therefore made to perform the tests once they were clinically stable. Both these infants had been asymptomatic for 14 days before testing. Body weight and crown-heel length were measured as described previously $y^{20}$ and expressed as sexspecific Z scores. ${ }^{21}$ All subjects were studied supine, during quiet sleep after sedation with an oral or rectal dose (60$100 \mathrm{mg} / \mathrm{kg}$ ) of chloral hydrate. Heart rate and oxygen saturation were monitored continuously during the tests $\left(\mathrm{CO}_{2} \mathrm{SMO}\right.$ Monitor, Novametrix Medical Systems, Wallingford, Connecticut, USA). The MBW technique was always performed before the raised volume technique.

\section{Measurement of lung function}

The equipment and procedure for performing MBW in infants was similar to that for preschool children, which has been described in detail previously. ${ }^{16}$ A face mask sealed to the infant's face using therapeutic putty was used for both the MBW and RVRTC tests. Flow was measured with a pneumotachometer, and gas concentrations using a respiratory mass spectrometer. In brief, each test consisted of two phases. During the wash-in phase, the infant inspired a dry air mixture containing $4 \%$ sulphur hexafluoride $\left(\mathrm{SF}_{6}\right)$. Wash-in was undertaken using a simple bias flow system and continued until the inspiratory and expiratory $\mathrm{SF}_{6}$ concentrations were stable and equal to $0.1 \%$, for a minimum of five breaths. The washout phase using room air started when the bias flow was disconnected during expiration. This washout phase continued until the end tidal $\mathrm{SF}_{6}$ concentration was consistently below $0.1 \%$ (ie $<1 / 40$ th of starting concentration). Functional residual capacity (FRC) and LCI were calculated as described previously ${ }^{22}{ }^{23}$ and are described in the supplementary file available online at http://thorax.bmj.com/supplemental. LCI is defined as the number of lung turnovers (ie, number of FRC measurements) required to clear the lungs to $1 / 40$ th of the starting concentration of the tracer gas. The mean FRC and LCI from three technically acceptable washouts were calculated. Z scores for FRC were calculated from published reference equations. ${ }^{24}$ As data available currently are insufficient to calculate $\mathrm{Z}$ scores for LCI during infancy, values that were greater than $1.96 \mathrm{SD}$ above the mean from healthy controls recruited to this study were considered to be raised.

Measurements of airway function at raised lung volume were performed as described previously ${ }^{1125}$ and in accordance with recent recommendations, ${ }^{9}$ using Jaeger Masterscreen ( ${ }^{*}$ see supplementary file online at http://thorax.bmj.com/ supplemental). Three to five lung inflations to a pressure of $30 \mathrm{~cm} \mathrm{H}_{2} \mathrm{O}(2.94 \mathrm{kPa})$ were administered before inflating the jacket to force expiration. This manoeuvre was repeated until at least three acceptable and reproducible FEFV curves were obtained. Parameters including forced expiratory volume in $0.5 \mathrm{~s}\left(\mathrm{FEV}_{0.5}\right)$, forced vital capacity (FVC), forced expiratory flow at $75 \%$ of the expired forced vital capacity $\left(\mathrm{FEF}_{75}\right)$ and forced expiratory flow between $25-75 \%$ FVC $\left(\mathrm{FEF}_{25-75}\right)$ were reported from the "best" raised volume curve, defined as the technically acceptable FEFV curve with the highest sum of FVC and $\mathrm{FEV}_{0.5} .{ }^{9} \mathrm{Z}$ scores for $\mathrm{FEV}_{0.5}, \mathrm{FEF}_{75}, \mathrm{FEF}_{25-75}$ and FVC were calculated from published equations. ${ }^{26} \mathrm{~A} \mathrm{Z}$ score $<-1.96$ (below the 2.5 th centile) was defined as diminished airway function.

\section{Data analysis}

Comparisons of group characteristics and respiratory function between the groups were performed using $t$ tests, MannWhitney U tests, $\chi^{2}$ or exact tests as appropriate (StatXact V 4.01). Receiver-operator characteristic curves were used to compare the diagnostic abilities of MBW and RVRTC parameters with respect to identifying abnormal lung function. Logistic regression models were used to investigate combined effects and the independence of any associations identified.

\section{Power of study}

Previous work from this department has shown that differences in $\mathrm{FEV}_{0.5}$ equating to at least $1 \mathrm{Z}$ score (ie, $1 \mathrm{SD}$ ) are likely to be observed between groups of infants with and without cystic fibrosis ${ }^{11}$ A sample size of 15 children per group would be sufficient to detect a difference equivalent to $1 \mathrm{SD}$ in FVC, $\mathrm{FEV}_{0.5}, \mathrm{FEF}_{75}$ and $\mathrm{FEF}_{25-75}$ between cystic fibrosis and control groups with $80 \%$ power at the 0.05 significance level.

\section{RESULTS}

Lung function measurements were attempted in 69 subjects ( 27 healthy controls; 42 cystic fibrosis). Data were incomplete in eight subjects as they woke before completing the test protocol, and data from one control subject failed the quality criteria for the RVRTC. Thus, successful measurements from both the MBW and RVRTC techniques were available from 60 infants (39 with cystic fibrosis). Table 1 summarises the group characteristics of these infants according to health status. It can be seen that, at birth, there were no significant differences between the groups in any of the background characteristics.

Table 1 Group characteristics at birth

\begin{tabular}{|c|c|c|c|}
\hline & CF $(n=39)$ & $\begin{array}{l}\text { Control } \\
(n=21)\end{array}$ & $\begin{array}{l}\text { Mean }(95 \% \mathrm{Cl}) \\
\text { difference* }\end{array}$ \\
\hline Boys (\%) & $12(31)$ & $9(43)$ & $-12(-36$ to 12$)$ \\
\hline Gestational age (weeks) & $39(2.1)$ & $39.7(1.2)$ & $-0.8(-1.6$ to 0.1$)$ \\
\hline Birth weight $(\mathrm{kg})$ & $3(0.6)$ & $3.3(0.4)$ & $-0.3(-0.6$ to 0.02$)$ \\
\hline Birth weight (Z score) & $-0.5(1.1)$ & $-0.3(0.8)$ & $-0.2(-0.8$ to 0.3$)$ \\
\hline $\begin{array}{l}\text { Maternal smoking during } \\
\text { pregnancy, } \mathrm{n}(\%)\end{array}$ & $12(31)$ & $6(29)$ & $2 \%(-22$ to 24$)$ \\
\hline $\begin{array}{l}\text { Maternal ethnic group, } \\
\mathrm{n}(\%) \text { white }\end{array}$ & $36(92)$ & $20(95)$ & $-3 \%(-16$ to 16$)$ \\
\hline $\begin{array}{l}\text { Maternal history of } \\
\text { asthma, } n(\%)\end{array}$ & $14(36)$ & $5(24)$ & $12 \%(-13$ to 33$)$ \\
\hline
\end{tabular}

CF, cystic fibrosis.

Results expressed as mean (SD) unless otherwise specified.

*Difference calculated as cystic fibrosis-control. 
Table 2 summarises the characteristics of the infants. Children with cystic fibrosis were studied at a similar mean age, although over a slightly wider age range than the controls (cystic fibrosis, 7.6-94.1 weeks; controls, 15.3-77.9 weeks). Mean (range) corrected postnatal age at diagnosis of cystic fibrosis was 10.3 (-2.6 to 64.1 ) weeks. The mean (range) time interval between diagnosis and lung function testing was 31.1 (4.7-86.3) weeks, this interval being similar in boys and girls.

After adjusting for age and sex, children with cystic fibrosis were found to be significantly shorter and lighter. Among children with cystic fibrosis, modes of presentation, prior hospital admission before lung function testing, presence of Pseudomonas aeruginosa infection on routine cough swabs, and weight and length $\mathrm{Z}$ scores at the time of the test did not vary between the sexes (see supplementary file at http://thorax. bmj.com/supplemental).

\section{Association between $\mathrm{LCl}$ and parameters derived from RVRTC}

Table 3 summarises the lung function results. For absolute values of RVRTC results, see table E2 available online at http:// thorax.bmj.com/supplemental.

The mean (SD) LCI for the healthy controls was $7.2(0.3)$. Thus, LCI values $>7.8$ (mean $+2 \mathrm{SD}$ ) were considered to be raised. Infants and young children with cystic fibrosis had significantly higher respiratory rate (RR), minute ventilation, FRC Z score and LCI (fig 1), and significantly lower values for all FEFV parameters than healthy controls (fig 2A-C). Although mean RR was significantly higher in young children with cystic fibrosis, when this was expressed as a Z score, ${ }^{27}$ only 5 of 39 patients $(13 \%)$ had an RR above the normal range $(>1.96 \mathrm{SD})$. Furthermore, there was no correlation between RR and either LCI or $\mathrm{FEV}_{0.5}$. $\mathrm{FRC}_{\mathrm{MBW}}$ in infants and young children with cystic fibrosis was significantly higher (mean (95\% CI) 0.73 (0.25 to 1.22) Z-score) compared with controls (table 3).

A total of 22 (56.4\%) infants and young children with cystic fibrosis had an abnormally high LCI (figs 1 and 2), all but nine of whom also had abnormally low forced flows and/or volumes (fig $2 \mathrm{~A}-\mathrm{C})$. In all, six (15\%) of the children with cystic fibrosis had abnormal RVRTC values in the presence of a normal LCI (fig $2 \mathrm{~A}-\mathrm{C}$ ). Thus, although both techniques detected abnormalities in a similar proportion of infants with cystic fibrosis, these groups did not represent exactly the same infants. This is further illustrated in fig 3, showing the area under the receiveroperator characteristic curve $\left(\mathrm{AUC}_{\mathrm{ROC}}\right)$ for $\mathrm{LCI}$ and $\mathrm{FEV}_{0.5} \mathrm{Z}$ score. Both parameters had similar power to discriminate between lung function in young children with and without cystic fibrosis (mean (SE) AUC $\mathrm{ROC}_{\text {C }}$ for LCI and $\mathrm{FEV}_{0.5} \mathrm{Z}$ score $0.834(0.05)$ and $0.836(0.05)$ respectively). Similar patterns were observed between LCI and $\mathrm{FEF}_{\%}$ parameters.
Among the healthy controls there was no difference in any of the lung function parameters according to sex. By contrast, while FVC and LCI were similar, $\mathrm{FEV}_{0.5}$ and $\mathrm{FEF}_{25-75}$ were significantly lower in girls with cystic fibrosis (mean (95\% CI) for girls - boys $-1.2(-2.1$ to -0.3$)$; $p=0.014$ for $\mathrm{FEV}_{0.5} \mathrm{Z}$ score; $1.2(-2.2$ to -0.15$) ; \mathrm{p}=0.026$ for $\mathrm{FEF}_{25-75} \mathrm{Z}$ score $)$.

The children with cystic fibrosis had increased LCI values and diminished $\mathrm{FEV}_{0.5} \mathrm{Z}$-scores. These variables were independently and significantly associated with cystic fibrosis in a logistic model (adjusted OR for an increase of one unit in LCI $=6.4$ ( 1.4 to 29.8), $\mathrm{p}=0.017$; adjusted OR for an increase in 1 $\mathrm{FEV}_{0.5} \mathrm{Z}$ score 0.36 (0.17 to 0.77$\left.), \mathrm{p}=0.009\right)$. This pattern of independence is illustrated in fig 2A. After accounting for differences in $\mathrm{FEV}_{0.5} \mathrm{Z}$ score and LCI, the other parameters ( $\mathrm{FVC}$ and $\mathrm{FEF}_{25-75}$ ) were not additionally predictive. When using both the MBW and RVRTC techniques, abnormalities were detected in $72 \%$ of infants with cystic fibrosis, $41 \%$ on both techniques and a further $15 \%$ by each of the two tests performed.

No clear pattern was observed between results from either the MBW or the RVRTC techniques with respect to mode of presentation, history of respiratory illness, or symptoms at test (see figs El-3 available online at http://thorax.bmj.com/ supplemental). Diminished forced flows and volumes in the presence of a normal LCI were, however, only found in those with recent cough (fig E3 A-C, available online at http:// thorax.bmj.com/supplemental).

\section{DISCUSSION}

This is the first study to compare the use of MBW and RVRTC in infants. Among this cohort, abnormalities were detected in $72 \%$ of infants with cystic fibrosis, $41 \%$ by both techniques and in a further $15 \%$ by each of the two separate tests. This suggests that, in contrast with studies in older children in whom spirometry has been shown to be a relatively insensitive means of detecting early changes in airway function, ${ }^{14}{ }^{15}$ the RVRTC detected airway abnormalities in a similar proportion (albeit different individuals) to the $\mathrm{MBW}$, with $\mathrm{FEV}_{0.5}$ and $\mathrm{FEF}_{25-75}$ being the most sensitive forced expiratory parameters. Thus, complementary information may be obtained by undertaking both tests. Girls with cystic fibrosis had significantly lower Zscores for $\mathrm{FEV}_{0.5}$ and $\mathrm{FEF}_{25-75}$ than boys with cystic fibrosis, but the number of boys studied was small $(n=12)$.

When expressed as Z scores, FRC was lower than predicted (mean (SD) $-1(0.9)$ ) in healthy subjects. This probably reflects differences in technique $\left(\mathrm{SF}_{6}\right.$ instead of $\mathrm{He}$ ), equipment (lower deadspace) and changes in protocol for data acquisition and analysis $^{19}$ in this study compared with studies from which prediction equations were derived. ${ }^{24}$ The significantly higher FRC in infants with cystic fibrosis compared with controls suggests the presence of hyperinflation in infants with cystic fibrosis.

Table 2 Group characteristics at test

\begin{tabular}{|c|c|c|c|c|}
\hline & CF $(n=39)$ & Control $(n=21)$ & Mean $(95 \% \mathrm{Cl})$ difference* & p Value \\
\hline Corrected PNA† (weeks) & $41.4(22)$ & $37.0(15.1)$ & $4.5(-5.2$ to 14.1$)$ & 0.359 \\
\hline Weight $(\mathrm{kg})$ & $8.1(1.8)$ & $8.5(1.2)$ & $-0.5(-1.4$ to 0.4$)$ & 0.286 \\
\hline Weight (Z score) & $-0.7(1.1)$ & $0.0(0.7)$ & $-0.7(-1.1$ to 0.2$) \ddagger$ & 0.005 \\
\hline Length $(\mathrm{cm})$ & $70.6(7.2)$ & $72.2(4.9)$ & $-1.6(-4.8$ to 1.5$)$ & 0.312 \\
\hline Length ( $Z$ score) & $0.08(1)$ & $1.1(0.8)$ & $-1.0(-1.5 \text { to } 0.5)^{*}$ & $<0.001$ \\
\hline Current maternal smoking (\%) & $11(28)$ & $5(24)$ & $4(-20$ to 25$)$ & 0.709 \\
\hline Current parental smoking (\%) & $19(49)$ & $8(38)$ & $11(-15$ to 34$)$ & 0.424 \\
\hline
\end{tabular}

$\mathrm{CF}$, cystic fibrosis; PNA, postnatal age.

Results are presented as mean (SD) unless specified.

*Difference calculated as CF-control.

*PNA corrected for gestational age (GA), ie actual PNA-(40-GA) weeks.

$\neq \mathrm{p}<0.05 ; \S \mathrm{p}<0.001$ 
Table 3 Lung function results compared by diagnosis

\begin{tabular}{|c|c|c|c|c|}
\hline & $\begin{array}{l}\text { Cystic fibrosis } \\
(n=39)\end{array}$ & $\begin{array}{l}\text { Healthy controls } \\
(n=21)\end{array}$ & Mean $(95 \% \mathrm{Cl})$ difference* & p Value \\
\hline Respiratory rate (per min) & $38.2(9.7)$ & $32.0(5.2)$ & $6.2(2.3$ to 10.0$)$ & 0.009 \\
\hline Respiratory rate (Z score)† & $0.8(1.4)$ & $-0.3(0.9)$ & $1.1(0.4$ to 1.8$)$ & 0.002 \\
\hline Tidal volume (ml) & $70.3(24.2)$ & $71.3(14.3)$ & $-1(-12.5$ to 10.6$)$ & 0.865 \\
\hline Minute ventilation $(\mathrm{ml} / \mathrm{min})$ & $2524(543)$ & $2235(374)$ & $287(22$ to 554$)$ & 0.035 \\
\hline $\mathrm{FRC}_{\mathrm{MBW}}(\mathrm{ml})$ & $170(54)$ & $156(38)$ & $14(-13$ to 41$)$ & 0.295 \\
\hline $\mathrm{FRC}_{\text {MBW }}$ (Z score) $\ddagger$ & $-0.27(1.0)$ & $-1(0.9)$ & $0.7(0.3$ to 1.2$)$ & 0.004 \\
\hline $\mathrm{LCl}$ & $8.4(1.5)$ & $7.2(0.3)$ & $1.2(0.7$ to 1.7$)$ & $<0.001$ \\
\hline $\mathrm{FEV}_{0.5}$ (Z score) & $-1.6(1.4)$ & $0.1(0.9)$ & $-1.7(-2.3$ to -1.1$)$ & $<0.001$ \\
\hline FVC (Z score) & $-1.2(1)$ & $-0.1(0.8)$ & $-1.1(-1.6$ to -0.6$)$ & $<0.001$ \\
\hline $\mathrm{FEF}_{75}$ (Z score) & $-1.8(1.5)$ & $-0.3(0.9)$ & $-1.4(-2.1$ to -0.8$)$ & $<0.001$ \\
\hline $\mathrm{FEF}_{25-75}$ (Z score) & $-1.9(1.5)$ & $-0.4(1)$ & $-1.5(-2.2$ to -0.9$)$ & $<0.001$ \\
\hline $\mathrm{FEV}_{0.5} / \mathrm{FVC}$ (Z score) & $-0.43(1.26)$ & $0.27(0.81)$ & $-0.70(-1.23$ to -1.16$)$ & 0.011 \\
\hline
\end{tabular}

FEF, mid-expiratory flow; FEV, forced expiratory volume; FVC, forced vital capacity; LCl, lung clearance index; FRC, functional residual capacity.

FRC $M B W$ corrected for equipment and mask deadspace.

Results are expressed as mean (SD) unless specified otherwise.

*Difference calculated as cystic fibrosis-control.

†According to prediction equation by Ranganathan et al. ${ }^{27}$

$\ddagger$ According to the prediction equations for He dilution by Stocks and Quanjer. ${ }^{24}$

\section{Strengths and limitations}

A potential limitation of this study is that the infants were not tested immediately after diagnosis or neonatal screening, as this cross-sectional study of children $<2$ years of age was undertaken as soon as our technology for the MBW technique had been adapted for infants. However, in a previous cohort of infants with cystic fibrosis, we found that $\mathrm{FEV}_{0.5}$ was significantly reduced shortly after diagnosis and did not seem to catch up during infancy and early childhood despite treatment. ${ }^{6}$ We had no "gold standard" of either inflammation or airway structural changes with which to relate our results.

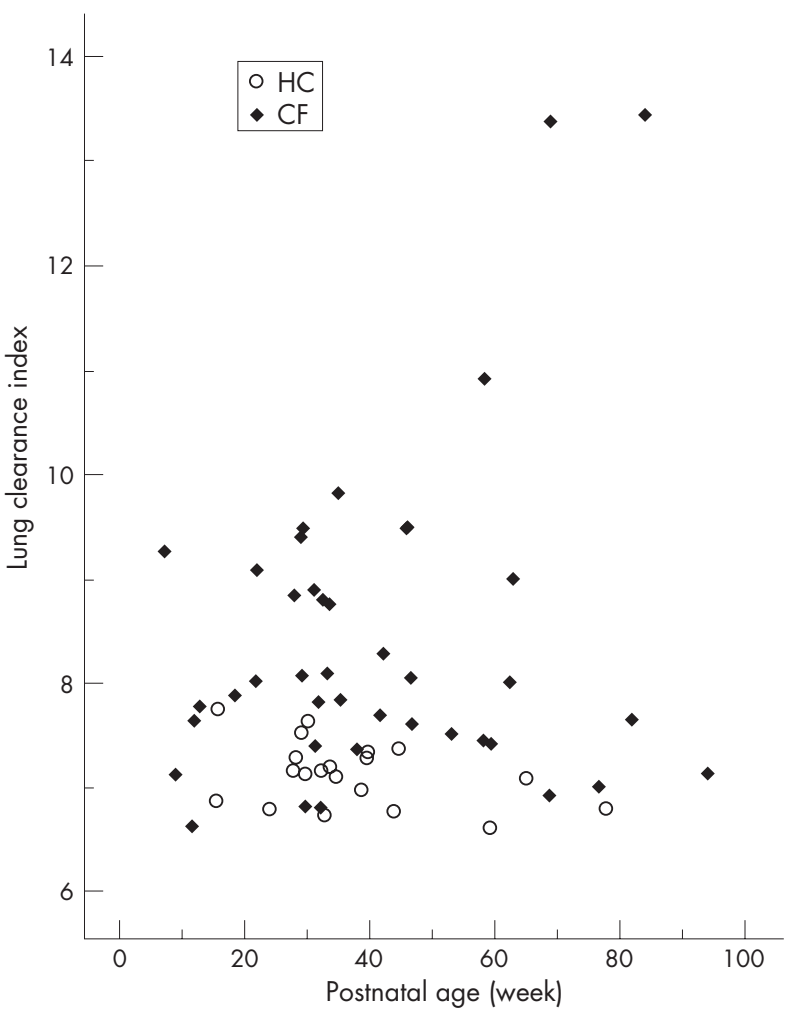

Figure 1 Lung clearance index plotted against postnatal age. Open circles represent healthy controls and closed symbols represent infants and young children with cystic fibrosis.
Significant relationships between an increased neutrophil count from bronchoalveolar lavage (BAL) and lung function have been shown during the first few years of life in children with cystic fibrosis, ${ }^{28}$ although parameters derived from BAL are rarely predictive in individuals owing to marked intersubject variability. At the time of this study, BAL was rarely undertaken in asymptomatic infants with cystic fibrosis at the London centres. Similarly, although it has been suggested that, in children with cystic fibrosis, modern imaging techniques such as high resolution computed tomography can identify structural changes long before spirometric changes are observed, ${ }^{29-31}$ routine use of high-resolution computed tomography in infants and young children with cystic fibrosis remains controversial, ${ }^{32}$ especially before ionising radiation had been reduced to current lower levels.

In addition to adapting the MBW for measurements in infants and young children, one of the greatest strengths of this study was the availability of prospectively recruited healthy control subjects which enabled direct comparison of results using identical techniques and measurement conditions as well as with published reference data, derived from children of similar age. ${ }^{25}{ }^{26}$ All RVRTC measurements and analyses were undertaken according to current guidelines and recommendations. ${ }^{9}$ Despite using slightly different equipment and software from that reported previously, the healthy infants had RVRTC results similar to those predicted ${ }^{26}$ and to those we have reported previously. ${ }^{11}$

Currently available data are insufficient to calculate accurate prediction equations or $\mathrm{Z}$ scores for LCI during infancy. Although it has been suggested that there may be a slight negative age dependency of LCI in healthy infants during the first months of life, ${ }^{33}$ most of the infants in this study were over 6 months of age when these effects were less marked, and all but one of the healthy controls had results that fell within the normal range established for preschool children, ie $<7.8$. $^{1}$ Although it can be argued that a higher upper limit for LCI of 8 should be applied to infants under 6 months of age, ${ }^{35}$ only one infant with cystic fibrosis would have been re-classified as having an LCI in the normal range had we used this approach.

\section{Relationship with previous studies of lung function in infants and young children with cystic fibrosis}

Despite the popularity of the tidal rapid thoracic compression technique, ${ }^{36-38}$ recent studies have suggested that the raised volume technique is a more sensitive means of identifying diminished airway function in infants with cystic fibrosis. ${ }^{11}{ }^{12}$ 
A

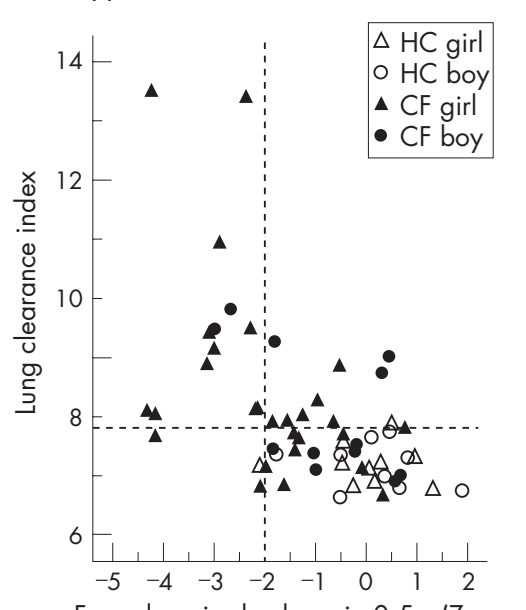

B

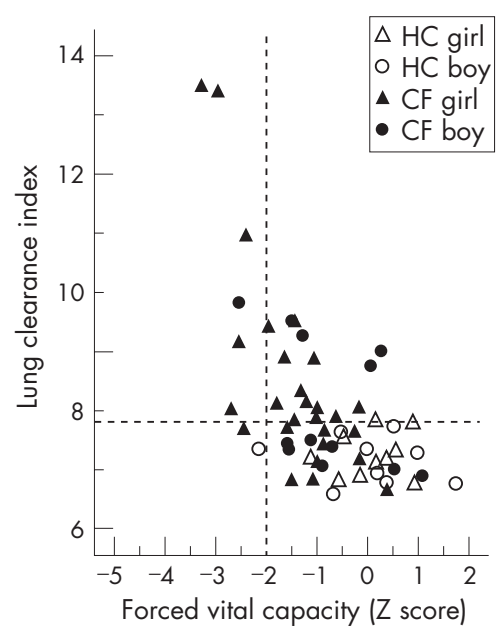

C

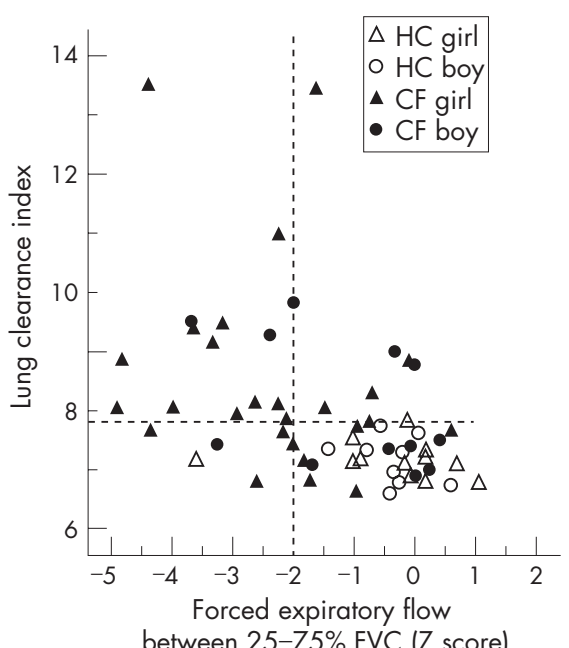

Figure 2 Relationship between lung clearance index (LCl) and (A) $\mathrm{FEV}_{0.5} \mathrm{Z}$ score, (B) FVC Z score and (C) $\mathrm{FEF}_{25-75} \mathrm{Z}$ score according to disease status and sex. The dashed horizontal line represents the upper range of normality for $\mathrm{LCl}$ in healthy infants. ${ }^{.}$The dashed vertical line represents the lower $95 \%$ limit of normality (ie, only $2.5 \%$ of healthy controls have $\mathrm{Z}$ scores below this level) for $\mathrm{FEV}_{0.5}, \mathrm{FVC}$ and $\mathrm{FEF}_{25-75}$. Any results to the left of this line are unusually low. FEFV Z scores were calculated from published reference equations. ${ }^{26}$ Infants in the right lower quadrant had normal results from both tests. This included all but one of the healthy controls who had an unusually low $\mathrm{FEF}_{25-75}$. Those in the left upper quadrant had abnormal results from both tests. Those in the right upper quadrant had abnormally high $\mathrm{LCl}$ but normal forced expiratory parameters, whereas those in the lower left quadrant had $\mathrm{LCl}$ within normal limits but diminished FEV or FEF parameters. Diminished flows in the presence of a normal $\mathrm{LCl}$ were predominantly observed among girls, and those with recent cough (see also fig E3 available online at http://thorax.bmj.com/supplemental. HC, healthy control; CF, cystic fibrosis.

There is now clear evidence that the MBW technique detects abnormal lung function more readily in both preschool and school age children with cystic fibrosis than spirometry, ${ }^{13} 15$ but this does not seem to be the case during infancy.

To our knowledge, only three published studies have used MBW to assess lung function in infants with cystic fibrosis, ${ }^{39-41}$ none of which assessed the relative sensitivity of the MBW compared with other techniques. Our study is the first to

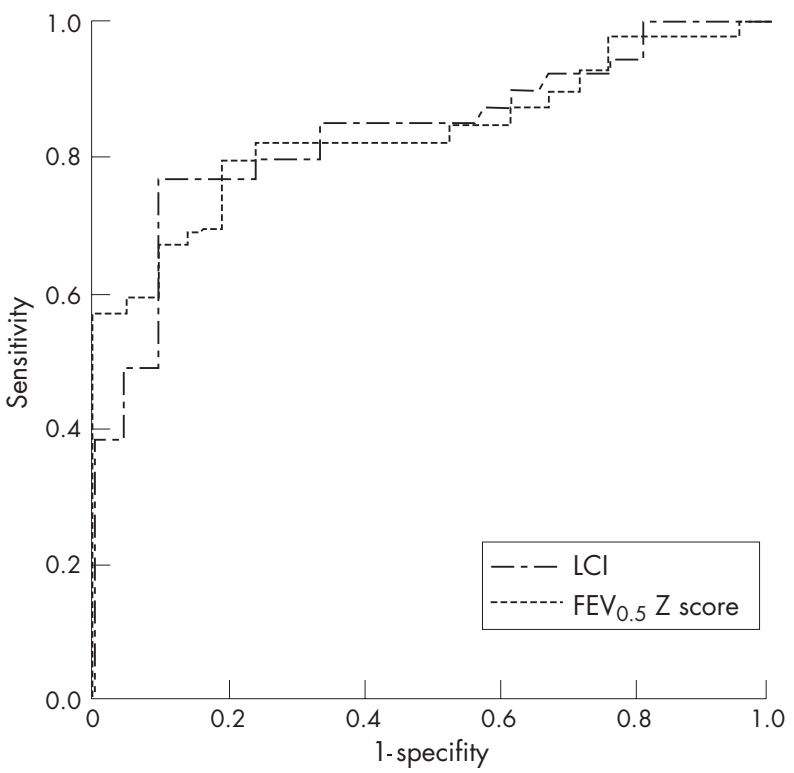

Figure 3 Receiver-operator curves for lung clearance index (LCI) and forced expired volume in $0.5 \mathrm{~s}\left(\mathrm{FEV}_{0.5}\right) \mathrm{Z}$ score. The outcome variable is the detection of cystic fibrosis lung disease. Both parameters had similar power to discriminate between lung function in young children with and without cystic fibrosis. compare FEFV indices derived from the RVRTC technique with LCI in infants and young children with cystic fibrosis, and emphasises the importance of reporting both flow and volume parameters from the RVRTC. ${ }^{25}{ }^{42}$ As reported previously, ${ }^{27}$ we found that the RR was significantly increased in infants and young children with cystic fibrosis, although there was no correlation between RR and LCI, $\mathrm{FEF}_{25-75}$ or $\mathrm{FEV}_{0.5}$. This suggests that these parameters may reflect different aspects of the early pathology of cystic fibrosis and that RR is influenced by factors other than airway obstruction or by airway properties that remain undetected by either of the techniques used.

Although Tepper et $a l^{41}$ reported that infants with cystic fibrosis presenting with a combination of failure to thrive and pulmonary symptoms had significantly lower pulmonary function compared with other modes of presentation, we did not observe this distinction between groups (see fig El available online at http://thorax.bmj.com/supplemental).

\section{Clinical significance of results}

In contrast with findings in preschool and school age children, in whom the LCI was found to be far more discriminative in identifying abnormal airway function than any spirometric parameter, ${ }^{13}$ our results suggest that, among infants, the two techniques have similar discriminative ability (fig 3). Given that tests were performed earlier in the course of the disease, we anticipated a lower incidence of airway abnormalities overall, and this was indeed the case with respect to the LCI, where only $56 \%$ of children had abnormally high values during infancy compared with $73 \%$ when tested during the preschool years $^{1}$ and virtually all children at school age. ${ }^{13}{ }^{15}$ By contrast, the proportion of children with cystic fibrosis with abnormal FEFV parameters during the first 2 years of life was much higher in both this and previous studies ${ }^{611}{ }^{43}$ than observed in such children during the preschool years. ${ }^{1}$ This increased sensitivity of the RVRTC during early life could reflect differences in technique, associated for example with the application of highly standardised lung inflations and external thoraco-abdominal compressions to force expiration, but 
probably also reflects developmental differences, including the high compliance of the chest wall and airways, reduced airway calibre and increased tendency to airway closure. Such differences make infants more prone to reduced airway function and respiratory problems even in the presence of relatively mild infection or inflammation, ${ }^{44}$ and could increase the sensitivity of FEFV manoeuvres to detect early lung disease. Differences in posture further complicate comparison of results between infants and older children. With young children being tested supine, the increased tendency to airway closure would be more exaggerated in the presence of lung pathology and may result in gas trapping in some children. With increasing airway closure in infants with cystic fibrosis lung disease, regions which are poorly ventilated and which would be reflected by a high LCI in older subjects may present an LCI within the normal range, despite reductions in FEFV parameters.

The highest values of LCI (>13.0) were observed in two cystic fibrosis infants with previous hospital admissions for bronchiolitis, both of whom also had abnormal FEFV parameters (fig 2). Despite recovering from their initial illness, both these infants were still on inhaled bronchodilator treatment at the time of testing. One of these infants had evidence of cough and wheeze at the time of the test whereas the other was asymptomatic (online supplement fig E3). Exclusion of these infants from the analysis did not change the level of significant difference in lung function parameters between those with cystic fibrosis and controls. Similarly, sex differences remained more marked in girls than in boys with cystic fibrosis.

Although healthy female infants have consistently been shown to have better airway function than their male counterparts, ${ }^{25} 44$ this was not apparent for the children with cystic fibrosis in this study in whom diminished airway function was more marked among the girls (fig 2). Although this finding will need to be verified in a larger cohort to ensure that it is not simply because of a type 1 error, this is the first study where airway function has been observed to be poorer in girls with cystic fibrosis during the first 2 years of life. A recent single centre study found no significant sex differences in either $\mathrm{FEV}_{1}$ or growth centiles in school age children with cystic fibrosis, ${ }^{45}$ but there have been many previous reports suggesting that affected male infants survive longer than female infants and that school age girls with cystic fibrosis exhibit significantly poorer lung function ${ }^{15}$ and higher respiratory morbidity and mortality, ${ }^{46}$ resulting in a 4 year difference in median survival $^{47}$ from their male counterparts.

The clinical significance of abnormal LCI or diminished forced expiratory parameters in infants with cystic fibrosis has yet to be determined. In lung disease, such as cystic fibrosis, asymmetric narrowing of the airway lumen is expected to occur at branch points throughout the airway tree, and may be caused by inflammation, scarring or obstruction by mucus, or by secondary changes in airway tone. Histopathology studies have shown that cystic fibrosis lung disease frequently affects the peripheral airways. ${ }^{48}$ However, the most important consideration is whether impaired gas mixing represents early changes of cystic fibrosis lung disease, which will subsequently progress, or is an epiphenomenon present in most children with cystic fibrosis. Results from this study have shown that abnormalities of both ventilation inhomogeneity and forced expiratory parameters can be detected in a large proportion of infants with cystic fibrosis during the first 2 years of life but, owing to the timing of the tests and the fact that they were applied to a population that was not diagnosed by neonatal screening, they cannot yet tell us whether either of these techniques has the ability to detect the onset of abnormal airway function, whether they are suitable as outcome variables for new treatments aimed specifically at preventing lung damage, and whether they will be useful for predicting the long-term outcome-questions that can be answered only by carefully designed longitudinal studies from birth to school age.

\section{CONCLUSIONS}

This study shows that a large proportion of infants with cystic fibrosis have abnormal lung function assessed either by MBW or by the raised volume technique, and that the two techniques provide complementary information during the early course of cystic fibrosis lung disease. These findings support the view that inflammatory and/or structural changes in the airways of children with cystic fibrosis start early in life, and have important implications regarding early detection and intervention if lung health is to be optimised in these children. The discrepancy between ventilation distribution and FEFV parameters in some children suggests that they reflect different structural or functional abnormalities of the airways and the lung parenchyma. To identify cystic fibrosis lung disease as early as possible, we suggest that both the RVRTC and MBW techniques be used, ideally starting shortly after birth in a population diagnosed by neonatal screening.

\section{ACKNOWLEDGEMENTS}

We thank the families who participated in this study, Dr Padmaja Subbarao for her help in data collection, and Professor Kate Costeloe and Dr Jane Hawdon for their support and permission to recruit infants from the Homerton University Hospital NHS Trust and the University College London Hospital, respectively. Rosemary Castle sadly passed away before this manuscript was written.

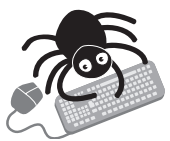

Supplementary data, table E2, figs E1-3 are available online on http://thorax.bmj.com/supplemental

\section{Authors' affiliations}

Sooky Lum, Henrik Liungberg, Georg Hülskamp, Rosemary Castle, Janet Stocks, Portex Anaesthesia, Intensive Therapy and Respiratory Medicine Unit, UCL, Institute of Child Health, London, UK

Per Gustafsson, Department of Pediatric Clinical Physiology, Queen Silvia Children's Hospital, Göteborg, Sweden

Andrew Bush, Department of Paediatric Respiratory Medicine, Royal Brompton Hospital, London, UK

Siobhán B Carr, Department of Child Health, Royal London Hospital, London, UK

Ah-fong Hoo, Sarath Ranganathan, Colin Wallis, Department of Paediatric Respiratory Medicine, Great Ormond Street Hospital for Children NHS Trust, London, UK

John Price, Hilary Wyatt, Department of Child Health, King's College Hospital, London, UK

John Stroobant, Department of Child Health, University Hospital Lewisham, London, UK

Angie Wade, Centre for Paediatric Epidemiology and Biostatistics, UCL, Institute of Child Health, London, UK

Funding: Portex Ltd (SL and JS); European Respiratory Society long-term research fellowship (HL); Innovative Medizinische Forschung, University of Münster and the Gesellschaft für Pädiatrische Pneumologie, Germany (GH) and Cystic Fibrosis Trust (SR). Research at the Institute of Child Health and Great Ormond Street Hospital for Children NHS Trust benefits from R\&D funding received from the NHS Executive.

Contributors: JS was responsible for the study design; SR set up the recruitment/referral process; $\mathrm{HL}, \mathrm{GH}, \mathrm{SL}$ and $\mathrm{A}-\mathrm{fH}$ recruited and measured infants and together with JS and PG, calculated and interpreted lung function parameters; RC was responsible for the database; SL and AW were responsible for statistical analysis; $S L$, JS and $P G$ drafted the manuscript. AB, SBC, JP, SR, JStr, CW and HW were LCFC collaborators 
and recruited infants with CF to the study. All authors contributed to interpretation and commented on the manuscript.

Competing interests: None.

This paper was presented in part at the American Thoracic Society Conference in Seattle, 2003.

\section{REFERENCES}

1 Aurora P, Bush A, Gustafsson P, et al. Multiple-breath washout as a marker of lung disease in preschool children with cystic fibrosis. Am J Respir Crit Care Med 2005; 171:249-56.

2 Dakin $\mathrm{CJ}$, Numa $\mathrm{AH}$, Wang $\mathrm{H}$, et al. Inflammation, infection, and pulmonary function in infants and young children with cystic fibrosis. Am J Respir Crit Care Med 2002; 165:904-10

3 Davis S, Jones $M$, Kisling J, et al. Comparison of normal infants and infants with cystic fibrosis using forced expiratory flows breathing air and heliox. Pediatr Pulmonol 2001;31:17-23.

4 Gustafsson PM, Aurora P, Lindblad A. Evaluation of ventilation maldistribution as an early indicator of lung disease in children with cystic fibrosis. Eur Respir J 2003;22:972-9.

5 Nixon GM, Armstrong DS, Carzino R, et al. Early airway infection, inflammation, and lung function in cystic fibrosis. Arch Dis Child 2002;87:306-11.

6 Ranganathan SC, Stocks J, Dezateux C, et al. The evolution of airway function in early childhood following clinical diagnosis of cystic fibrosis. Am J Respir Crit Care Med 2004; 169:928-33.

7 Aurora P, Wade A, Whitmore P, et al. A model for predicting life expectancy of children with cystic fibrosis. Eur Respir J 2000;16:1056-60.

8 Sharma R, Florea VG, Bolger AP, et al. Wasting as an independent predictor of mortality in patients with cystic fibrosis. Thorax 2001;56:746-50.

9 ATS-ERS Consensus Statement. Raised volume forced expirations in infants: recommendations for current practice. Am J Respir Crit Care Med 2005; 172:1463-71.

10 Ranganathan S, Dezateux CA, Bush A, et al. Airway function in infants newly diagnosed with cystic fibrosis. Lancet 2001;358:1964-5.

11 Ranganathan SC, Bush A, Dezateux C, et al. Relative ability of full and partial forced expiratory maneuvers to identify diminished airway function in infants with cystic fibrosis. Am J Respir Crit Care Med 2002;166:1350-7.

12 Turner DJ, Lanteri CJ, Le Souëf PN, et al. Improved detection of abnormal respiratory function using forced expiration from raised lung volume in infants with cystic fibrosis. Eur Respir J 1994;7:1995-9.

13 Aurora P, Gustafsson P, Bush A, et al. Multiple breath inert gas washout as a measure of ventilation distribution in children with cystic fibrosis. Thorax 2004;59: 1068-73.

14 Tiddens HA. Detecting early structural lung damage in cystic fibrosis. Pediatr Pulmonol 2002;34:228-31.

15 Kraemer R, Blum A, Schibler A, et al. Ventilation inhomogeneities in relation to standard lung function in patients with cystic fibrosis. Am J Respir Crit Care Med 2005;171:371-8.

16 Gustafsson PM. Inert gas washout in preschool children. Paediatr Respir Rev 2005;6:239-45

17 Paiva M, Engel LA. Gas mixing in the lung periphery. In: Chang HK, Paiva M, eds. Respiratory physiology: an analytical approach. New York: Marcel Dekker, 1989:245-76.

18 Dezateux C, Lum S, Hoo AF, et al. Low birth weight for gestation and airway function in infancy: exploring the fetal origins hypothesis. Thorax 2004:59:60-6.

19 Hulskamp G, Hoo AF, Liungberg $\mathrm{H}$, et al. Progressive decline in plethysmographic lung volumes in infants: physiology or technology? Am J Respir Crit Care Med 2003; 168:1003-9.

20 Gaultier C, Fletcher M, Beardsmore C et al. Measurement conditions. In: Stocks J Sly PD, Tepper RS, Morgan WJ, eds. Infant respiratory function testing. New York: John Wiley \& Sons, 1996:29-44

21 Freeman JV, Cole TJ, Chinn S, et al. Cross sectional stature and weight reference curves for the UK, 1990. Arch Dis Child 1995;73:17-24

22 Edelman $\mathrm{NH}$, Mittman $\mathrm{C}$, Norris $\mathrm{AH}$, et al. Effects of respiratory pattern on age differences in ventilation uniformity. J Appl Physiol 1968;24:49-53.
23 Larsson A, Jonmarker $\mathrm{C}$, Werner $\mathrm{O}$. Ventilation inhomogeneity during controlled ventilation. Which index should be used? J Appl Physiol 1988;65:2030-9.

24 Stocks J, Quanjer PH. Reference values for residual volume, functional residual capacity and total lung capacity. Eur Respir J 1995;8:492-506.

25 Lum S, Hoo AF, Dezateux C, et al. The association between birthweight, sex, and airway function in infants of nonsmoking mothers. Am J Respir Crit Care Med $2001 ; 164: 2078-84$.

26 Jones M, Castile R, Davis S, et al. Forced expiratory flows and volumes in infants. Am J Respir Crit Care Med 2000;161:353-9.

27 Ranganathan SC, Goetz I, Hoo AF, et al. Assessment of tidal breathing parameters in infants with cystic fibrosis. Eur Respir J 2003;22:761-6.

28 Brennan S, Hall GL, Horak F, et al. Correlation of forced oscillation technique in preschool children with cystic fibrosis with pulmonary inflammation. Thorax 2005;60:159-63.

29 Brody AS, Klein JS, Molina PL, et al. High-resolution computed tomography in young patients with cystic fibrosis: distribution of abnormalities and correlation with pulmonary function tests. J Pediatr 2004;145:32-8.

30 de Jong PA, Muller NL, Pare PD, et al. Computed tomographic imaging of the airways: relationship to structure and function. Eur Respir J 2005;26:140-52.

31 Long FR, Williams RS, Castile RG. Structural airway abnormalities in infants and young children with cystic fibrosis. J Pediatr 2004;144:154-61.

32 de Jong PA, Mayo JR, Golmohammadi K, et al. Estimation of cancer mortality associated with repetitive computed tomography scanning. Am J Respir Crit Care Med 2006;173:199-203.

33 Lum S, Gustafsson P, Stanojevic S, et al. Gas mixing efficiency improves during the 1st year of life [abstract]. Eur Respir J 2006;28(Suppl 50):834s.

34 Pillow JJ, Hulskamp G, Stocks J. Lung clearance index changes with maturation in preterm neonates [abstract]. Eur Respir J 2005;26(Suppl 49):6s.

35 Aurora P, Kozlowska W, Stocks J. Gas mixing efficiency from birth to adulthood measured by multiple-breath washout. Respir Physiol Neurobiol 2005; 148:125-39.

36 Beardsmore CS, Thompson JR, Williams A, et al. Pulmonary function in infants with cystic fibrosis: the effect of antibiotic treatment. Arch Dis Child 1994:71:133-7.

37 Gappa M, Ranganathan S, Stocks J. Lung function testing in infants with cystic fibrosis: lessons from the past and future directions. Pediatr Pulmonol $2001 ; 32: 228-45$

38 Tepper RS, Montgomery GL, Ackerman V, et al. Longitudinal evaluation of pulmonary function in infants and very young children with cystic fibrosis. Pediatr Pulmonol 1993;16:96-100.

39 Gustafsson PM, Kallman S, Liungberg $\mathrm{H}$, et al. Method for assessment of volume of trapped gas in infants during multiple-breath inert gas washout. Pediatr Pulmonol 2003:35:42-9.

40 Schibler A, Schneider M, Frey U, et al. Moment ratio analysis of multiple breath nitrogen washout in infants with lung disease. Eur Respir $J$ 2000;15:1094-101.

41 Tepper RS, Hiatt $P$, Eigen $\mathrm{H}$, et al. Infants with cystic fibrosis: pulmonary function at diagnosis. Pediatr Pulmonol 1988;5:15-8.

42 Jones MH, Howard J, Davis S, et al. Sensitivity of spirometric measurements to detect airway obstruction in infants. Am J Respir Crit Care Med 2003; 167:1283-6.

43 Castile RG, Iram D, McCoy KS. Gas trapping in normal infants and in infants with cystic fibrosis. Pediatr Pulmonol 2004;37:461-9.

44 Stocks J, Hislop AA. Structure and function of the respiratory system: developmental aspects and their relevance to aerosol therapy. In: Bisgaard $\mathrm{H}$, O'Callaghan C, Smaldone GC, eds. Drug delivery to the lung: clinical aspects. New York: Marcel Dekker, 2001:47-104

45 Verma N, Bush A, Buchdahl R. Is there still a gender gap in cystic fibrosis? Chest 2005; 128:2824-34.

46 Zemel BS, Jawad AF, FitzSimmons S, et al. Longitudinal relationship among growth, nutritional status, and pulmonary function in children with cystic fibrosis: analysis of the Cystic Fibrosis Foundation National CF Patient Registry. J Pediatr 2000;137:374-80.

47 Davis PB. The gender gap in cystic fibrosis survival. J Gend Specif Med 1999;2:47-51

48 Davis PB. Pulmonary disease in cystic fibrosis. In: Chernick V, Boat TF, Wilmott RW, Bush A, eds. Kendig's disorders of the respiratory tract in children. Philadelphia: Saunders Elsevier, 2006:873-86. 